\title{
Epidemiological considerations in transgender health: A systematic review with focus on higher quality data
}

\section{[Author final manuscript]}

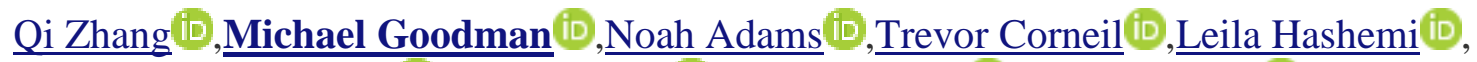

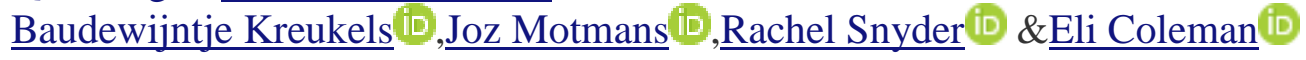

Published online: 15 Apr 2020

Cite as: Zhang, Q., Goodman, M., Adams, N., Corneil, T., Hashemi, L., Kreukels, B., Motmans, J., Snyder, R., \& Coleman, E. (2020). Epidemiological considerations in transgender health: A systematic review with focus on higher quality data. International Journal of Transgender Health, 1-13. doi:10.1080/26895269.2020.1753136

KEY WORDS: transgender; gender diverse; gender nonconforming; epidemiology; population; systematic review; PRISMA 


\section{ABSTRACT}

Background: High quality data pertaining to the size of the transgender and gender diverse (TGD) population are scant, however, several recently published studies may provide more reliable contemporary estimates.

Aims: To summarize the estimated number and proportion of TGD individuals overall and across age groups, based on most accurate data.

Methods: This systematic review focused on recent studies (published from 2009 through 2019) that utilized sound methodology in assessing the proportion of TGD people in the general population. Publications were included if they used clear definitions of TGD status, and calculated proportions based on a well-defined sampling frame. Nineteen eligible publications represented two broad categories of studies: those that used data from large health care systems; and those that identified TGD individuals from population surveys.

Results: Among health system-based studies, TGD persons were identified using relevant diagnostic codes or clinical notes. The proportions of individuals with a TGD-relevant diagnosis or other recorded evidence ranged between 17 and 33 per 100,000 enrollees. In population surveys TGD status was ascertained based on self-report with either narrow or broad definitions. The survey-based estimates were orders of magnitude higher and consistent across studies using similar definitions. When the surveys specifically inquired about 'transgender' identity, the estimates ranged from $0.3 \%$ to $0.5 \%$ among adults, and from $1.2 \%$ to $2.7 \%$ among children and adolescents. When the definition was expanded to include broader manifestations of 'gender diversity', the corresponding proportions increased to $0.5-4.5 \%$ among adults and $2.5-8.4 \%$ among children and adolescents. Upward temporal trends in the proportion of TGD people were consistently observed. Conclusions: Current data indicate that people who self-identify as TGD represent a sizable and increasing proportion of the general population. This proportion may differ, depending on inclusion criteria, age, and geographic location, but well-conducted studies of similar type and design tend to produce comparable results. 


\section{INTRODUCTION}

Reliable up-to-date information regarding the number and the proportion of transgender and gender diverse (TGD) people in the general population is necessary for data-driven planning, funding, and delivery of appropriate and necessary transgender health care services (Deutsch, 2016; Goodman et al., 2019). Accurate estimates of the size of the TGD population are also essential to enable evidence-based social policy that protects against stigma and discrimination, to inform governments about the need for legal gender recognition of both transgender and gender diverse people, and to educate insurance companies on how best to provide coverage for TGD persons (Meerwijk \& Sevelius, 2017). As our understanding of the TGD population improves, a better understanding of the epidemiology will support advances in research, innovation, and knowledge base that will improve health and wellbeing of TGD people. These considerations motivated the present review, which constitutes a part of the forthcoming Standards of Care for the Health of Transsexual, Transgender, and Gender Nonconforming People - Version 8 (SOC-8). The seventh edition of the SOC identified only a small number of articles that attempted to estimate the size of the TGD population and, overall, characterized the state-of-the-science as "a starting point" that required further systematic study (Coleman et al., 2012).

As epidemiological evidence pertaining to the size and distribution of TGD population is reviewed, it is important not to use the terms 'incidence' and 'prevalence' to avoid pathologizing TGD people (Adams et al., 2017; Bouman et al., 2017). The term 'incidence' may be especially inappropriate because it assumes that TGD status has an easily identifiable time of onset. Throughout this article, we use the terms 'number' and 'proportion' when referring to the absolute and the relative size of the TGD population, respectively. 
In recent years, a number of reviews sought to synthesize the available literature regarding this issue (Arcelus et al., 2015; Collin, Reisner, Tangpricha, \& Goodman, 2016; Goodman et al., 2019; Meier \& Labuski, 2013), but the rapidly increasing number of published studies demands continuous re-evaluation of the available data. Moreover, the main methodological limitation of most previously published studies is the lack of clear sampling frame. Many of the published studies, especially those conducted more than a decade ago first assessed the number of patients seen at a particular clinical center and then divided that number by an approximated population size. This was unlikely to produce an accurate estimate, because the numerator in the calculations is not necessarily included in the denominator. These methodological shortcomings have been discussed previously (Collin et al., 2016), and it is encouraging that several of the recently published studies were able to employ a more formal statistical approach in calculating the size and distribution of the TGD populations (Goodman et al., 2019). With these considerations in mind, the goal of the current assessment of the evidence is to focus specifically on recent (published within the last decade) studies that utilized sound methodology in identifying TGD people within a well-defined sampling frame. It is expected that these types of studies are capable of providing more accurate contemporary estimates.

\section{METHODS}

This review followed the guidelines of The Preferred Reporting Items for Systematic Reviews and Meta-Analyses (Moher, Liberati, Tetzlaff, \& Altman, 2009). We conducted the initial literature search of PubMed and PsycINFO electronic databases using combinations of the broad search terms "transgender", "population" and "epidemiology" separated by the Boolean 'operator AND'. Following screening of titles and abstracts, we excluded duplicates and records 
that did not address the relevant research question. For example, studies that examined HIV prevalence among TGD people, or evaluated various aspects of access to TGD care, but did not report the proportion of the TGD population were not considered further.

Records retained after initial screening underwent a full text review to identify eligible studies. Secondary references of retrieved articles and review publications were also examined to identify studies not captured by the electronic search. Publications were included in the final review if they: 1) appeared in press in 2009 or later; 2) were published in English; 3) used a clear definition of TGD status; 4) calculated proportions of TGD people based on a well-defined population denominator; and 5) were peer-reviewed.

At least two authors (MG and QZ, or MG and LH) independently reviewed each article. Data extracted from relevant studies were categorized according to the following characteristics:

- Source of data, time interval, and population characteristics

- Citation

- Definition of TGD status (numerator)

- Number of people in the numerator

- Source and size of denominator

- The estimated proportions of TGD people

When one of the parameters (e.g., the denominator or the numerator) was not available, the missing value was calculated from the data included in the original article. Following data extraction the studies were grouped into two broad categories: those that used medical records to identify TGD people in a particular health care system, and those that identified TGD individuals from population surveys. While health care-systems-based studies were primarily focused on adults, the second (survey-based) category was further subdivided into two groups: studies that 
conducted surveys primarily among adults and studies that were based on surveys of children and adolescents. The estimated proportions of TGD people in each group of survey-based studies were reported overall and where available separately for persons assigned male or female sex at birth (AMAB and AFAB, respectively).

\section{RESULTS}

Following screening of titles and full text reviews, 19 articles met the eligibility criteria (Figure 1). Of those five publications reported proportions of TGD people among individuals enrolled in large health care systems, eight articles presented results from surveys of predominantly adult populations (although two studies included a small percentage of adolescents), and the remaining six studies were based on surveys of schoolchildren or their parents.

\section{<FIGURE 1> HERE}

\section{Proportions of TGD Individuals among Persons Enrolled in Health Care Systems}

The five health systems-based studies are summarized in Table 1. All of those studies were conducted in the United States and all used diagnostic codes, alone or in combination with other evidence in clinical notes, to define TGD status. Two studies estimated proportions of TGD people among individuals who receive care within the Veterans Health Affairs (VHA) health system. The Veterans Health Administration (VHA) is the largest integrated health care system that includes 1,170 medical centers and 1,074 outpatient clinics and provides care to over 9 million individuals (US Department of Veterans Affairs, 2019). The first of the two studies (Blosnich et al., 2013) used VHA electronic health records for the period 2002 through 2011. 
The numerator for the study included individuals that had received an International Classification of Diseases Ninth Edition (ICD-9; WHO, 1978) diagnostic code of either 302.85 (gender identity disorder) or 302.6 (gender identity disorder not otherwise specified, although this code is often reserved for children). Using the VA data and electronic record database to define the denominator, the authors reported proportion estimates for different years starting in 2002 $(12.52 / 100,000)$ and ending in $2011(22.88 / 100,000)$. In a more recent VHA study of similar design, the numerator was expanded to include ICD-9 code 302.5 (transsexualism); the resulting proportion of TGD veterans in 2013 increased to 32.9/100,000 (Kauth et al., 2014). The age distributions of the population in the two VHA based studies are not provided. Another health systems-based study evaluated electronic health records data at Kaiser Permanente sites in Georgia, Northern California, and Southern California in the US (Quinn et al., 2017). These health plans provide care to approximately 8 million members who enroll through their employers, government programs such as Medicaid and Medicare, or individually. The patient populations of Kaiser Permanente are demographically and socioeconomically representative of the corresponding communities (Koebnick et al., 2012). The numerator in the Quinn et al. (2017) study was ascertained using computer assisted search and review of diagnostic information and free text to identify TGD individuals. The proportions of TGD Kaiser Permanente enrollees across the entire population increased at each of the three participating sites, but the data were not presented for different age groups. In 2006, the estimates per 100,000 enrollees were 3.5, 5.5, and 17 in Georgia, Southern California, and Northern California, respectively. By 2014, the corresponding estimates increased to 38, 44 and 75 . Two recent publications relied on ICD codes to identify TGD individuals among Medicare beneficiaries. Medicare is the federal health insurance program for people who are 65 years of age or older, younger individuals with certain 
disabilities and patients diagnosed with end-stage renal disease (US Centers for Medicare \& Medicaid Services, 2004). The first study (Dragon, Guerino, Ewald, \& Laffan, 2017) examined data for 2015 and used only ICD-9 codes for transsexualism and gender identity disorder to identify a total of 7454 TGD individuals among 39,136,229 Medicare enrollees for an estimated proportion of 19 per 100,000. Although the total population included persons from 18 to over 85 years of age, it is important to point out that Medicare is considered representative of the general population only in the age group 65 and older. In a more recent study (Ewald et al., 2019) Medicare data were examined for a period from 2010 through 2016 using both ICD-9 and ICD10 codes (WHO, 1992). The studies observed a more than four-fold increase in the proportion of TGD Medicare beneficiaries from 4.2 per 100,000 in 2010 to 17 per 100,000 in 2016.

\section{$<T A B L E$ 1 $>$ HERE}

\section{$\underline{\text { Proportions of TGD People in Surveys of Primarily Adult Populations }}$}

Eight studies summarized in Table 2, used survey-based data to estimate the proportion of adults (primarily, but not exclusively, over the age of 18 years) who self-identified as TGD. Four studies were based in the US, while the rest were conducted in Sweden, The Netherlands, Belgium and Taiwan. Two US studies took advantage of the Behavioral Risk Factor Surveillance Study (BRFSS), which is an annual telephone survey conducted in all 50 states and US territories. The first of these studies analyzed data collected between 2007 and 2009, in the State of Massachusetts (Conron, Scott, Stowell, \& Landers, 2012). This survey, administered to 28,176 adults (ages 18-64 years) contained the following module: "Some people describe themselves as transgender when they experience a different gender identity from their sex at 
birth. For example, a person born into a male body, but who feels female or lives as a woman. Do you consider yourself to be transgender?" A total of 131 participants responded 'yes' to this question, corresponding to a proportion of 0.5\%. In 2014 the same BRFSS question was adopted by 19 states and the territory of Guam. TGD individuals made up $0.53 \%$ of participants at least 18 years of age (average and range not reported) across all participating sites (Crissman, Berger, Graham, \& Dalton, 2017). This estimate was based on a total of 691 responses. Of these, 363 participants self-identified as "transgender, male-to-female" (AMAB), 212 as "transgender female-to-male" (AFAB), while, for the remaining 116 gender diverse participants, data on sex assigned at birth were not available. Reisner and colleagues performed a secondary analysis of the Growing Up Today Study (GUTS), a prospective cohort of US young adults recruited in 2005 at an average age of 21 years (Reisner, Conron, et al., 2014). In collaboration with the GUTS team, the authors added a two-step gender identity measure to the 2010 survey. The twostep approach, which is increasingly used in research and starting to be applied in clinical practice, first asks participants to indicate their sex assigned at birth, and then inquires about their current gender identity (Grasso et al., 2019; Reisner, Biello, et al., 2014) In the GUTS survey the second question was given response options of "Female," "Male," "Transgender, “and "Do not identify as female, male or transgender." Among 7,831 survey respondents, 26 $(0.33 \%)$ reported a gender identity that differed from their sex assigned at birth. Of those, 7 $(0.09 \%)$ expressed a "cross-sex identity", $5(0.06 \%)$ self-identified as transgender, and 14 $(0.18 \%)$ reported an identity most consistent with a non-binary category.

The two step gender identity measure was also tested, along with other approaches, in a series of relatively small studies conducted in San Francisco, California (Tate, Ledbetter, \& Youssef, 2013). The first study ( $n=238)$ recruited two samples of college students in the age range from 18 
to 48 years (average 23-24 years) and tested a single question method ("What is your gender?") that allowed options 'male,' 'female', 'transgender' or 'other' with two study participants $(0.8 \%)$ self-identified as transgender. The second study included a somewhat larger group of college students representing three different samples with a mean age of 23 years (age data only available for two of three samples) and used a two-step method: the first question was "What is your current gender?', with answer options 'female', 'male', 'transgender', 'genderqueer', or 'intersex'. The second question "What gender were you assigned at birth?” had answer options 'female', 'male', or 'intersex'. Among 364 study participants $6(1.7 \%)$ reported that their gender identity differed from sex assigned at birth. The third study also used the same two-step approach, but recruited two samples of participants (average ages 27 and 30 years) in the community rather than among college students. The overall proportion of TGD individuals among 388 participants in the third study was $3.1 \%$ with 12 respondents self-identifying as TGD; 3 trans female, 3 trans male and 6 non-binary. Kuyper and Wijsen estimated the proportion of TGD adolescent and adult residents in the Netherlands using an internet-based survey administered to a representative sample of the Dutch population $15-70$ years of age (Kuyper \& Wijsen, 2014). The study included a small proportion of adolescents grouped together with young adults in the age category $15-24$ years; however, the majority of participants (83\%) were 25 years of age or older. The study sample included 8,064 participants who were asked questions regarding gender identity. When assessing gender identity, participants were asked to score the following two questions using a 5-point Likert scale: "Many men experience themselves clearly as a man. For some men, this is not (completely) the case. Could you indicate to which degree you psychologically experience yourself as a man?" and "Could you indicate to which degree you psychologically experience yourself as a woman?" A person was considered gender 
ambivalent if the same answer was given to both statements (scores 1-1; 2-2;3-3; 4-4; and 55). Gender incongruence was defined as a lower score assigned to sex assigned at birth than current gender identity. The proportions of participants reporting incongruent gender identity were $1.1 \%$ for $\mathrm{AMAB}$ and $0.8 \%$ for $\mathrm{AFAB}$; and the corresponding estimates for ambivalent gender identity were $4.6 \%$ and $3.2 \%$. A similar study estimated the proportion of TGD residents (ages range 14-80 years, $73 \%$ over the age of 29) in the Flanders region of Belgium (Van Caenegem et al., 2015). Eligible participants were randomly selected from the Belgian National Register to draw a representative sample, of which, 1,799 (48\%) completed the survey. Information pertaining to gender identity and expression was collected via a computer-assisted personal interview. Participants were asked to score the following statements: "I feel like a woman," and "I feel like a man." on a 5-point Likert scale. Using the same definitions of gender incongruence and ambivalence as those in the Dutch study (Kuyper and Wijsen, 2014), the proportion of gender incongruence was estimated to be $0.7 \%$ for AMAB people and $0.6 \%$ for AFAB people. The corresponding estimates for gender ambivalence, among AMAB and AFAB people, were even higher at $2.2 \%$ and $1.9 \%$, respectively. A study of Taiwanese university students with an average age of 19.6 years (range not reported) conducted interviews with 5,010 participants using the Adult Self-Report Inventory-4 instrument (Lai, Chiu, Gadow, Gau, \& Hwu, 2010). Self-reported "gender dysphoria" was determined based on a response to the statement "I wish I was the opposite sex." Responses "often" and "very often" were interpreted as evidence of gender dysphoria. The use of this rather loose definition produced high estimated proportions of TGD people: $1.9 \%$ for $\mathrm{AMAB}$ people and $7.3 \%$ for $\mathrm{AFAB}$ people. A recent population-based study evaluated the proportion of TGD people among 50,157 adult residents of Stockholm County, Sweden (Ahs et al., 2018). With respect to age, participants were categorized 
as $22-29,30-44,45-66$, and $67+$ years old. The numerator was determined by asking participants the following question: "I would like hormones or surgery to be more like someone of a different sex." Two additional items inquired were designed to identify individuals experiencing gender incongruence: "I feel like someone of a different sex", and "I would like to live as or be treated as someone of a different sex." Responses to each item followed a 4-point Likert scale. Using weighting to account for stratified sampling design, the authors reported that the desire for either hormone therapy or gender affirming surgery was reported by $0.5 \%$ of participants. Individuals who expressed feeling like someone of a different sex and those who wanted to live as or be treated as a person of another sex constituted $2.3 \%$ and $2.8 \%$, of the total sample, respectively. When the data were presented by age, the proportion of persons who felt like someone of a different sex ranged from $1 \%$ in those 67 years of age or older to $4 \%$ in the youngest (22-29 years) age group. The corresponding age-specific proportions of those who wanted to live as or be treated as a person of another sex ranged from $1 \%$ to $6 \%$ in the oldest and the youngest group, respectively.

\section{<TABLE 2> HERE}

\section{Proportions of TGD Participants in Surveys of School Age Children}

The literature on the population proportions of TGD youth (persons under 19 years of age) is summarized in Table 3. Five studies examined this question by conducting surveys in schools and another study collected information from parents and primary caregivers. Almeida and colleagues used data from the 2006 survey of $9^{\text {th }}$ to $12^{\text {th }}$ grade students (age range 13-19 years, mean 16 years) in Boston Public Schools in the US (Almeida, Johnson, Corliss, Molnar, \& 
Azrael, 2009). Survey participants were asked whether they considered themselves to be “transgendered", for which the available answers were 'yes', 'no', and 'don't know'. A more precise definition of 'being "transgendered" was not given. Of 1,032 completed surveys, administered at 18 schools, $17(1.6 \%)$ indicated that the respondents self-identified as transgender, 11 of which were filled out by adolescents with a reported 'female sex'. A 2012 national cross-sectional survey in New Zealand collected information on TGD identity among 8,166 high school students (Clark et al., 2014). The final sample included 8,164 participants of whom $65 \%$ were under the age of 16 years. However, the details of the age distribution are not reported. The numerator was based on the responses to the question "Do you think you are transgender? This is a girl who feels like she should have been a boy, or a boy who feels like he should have been a girl (e.g., Trans, Queen, Fa'faffine, Whakawahine, Tangata ira Tane, Genderqueer)?" Possible answers were 'no', 'yes', 'I am not sure', and 'I don't understand the question'. Much earlier in the survey there was a query "What sex are you?" with response options limited to 'male' or 'female'. A total of 96 students (1.2\%) self-identified as TGD and $201(2.5 \%)$ reported they were not sure and $1.7 \%$ did not understand the question. Notably, only about one-third of TGD participants reported having disclosed their TGD identity. Another school-based survey that recorded participants' self-reported TGD identity was a 2016 study of $9^{\text {th }}$ and $11^{\text {th }}$ grade students (ages 14-18 years) in Minnesota (US) (Eisenberg et al., 2017). Of the 80,929 survey respondents, 2,198 students $(2.7 \%)$ reported being TGD. The proportion of TGD adolescents was higher among racial/ethnic minorities, but appeared similar in metropolitan and non-metropolitan areas of the state. The most recently published school-based study in the US presented results of a 2015 survey conducted in Florida and California (Lowry et al., 2018). The Youth Risk Behavior Survey was administered in a sample of 6082 students in grades 9-12 
(approximate age range 13-19 years, specific distribution not reported) to identify gender diverse participants. "High gender-nonconforming" students who were AMAB reported being very/mostly/somewhat feminine or AFAB who reported being very/mostly/somewhat masculine. Using these definitions, the proportions of TGD participants were reported to be $13 \%$ among AMAB people, $4 \%$ among AFAB people, and $8.4 \%$ overall.

Only one study examined the proportion of self-identified TGD children in a younger age group. Shields et al. analyzed the data from a 2011 Youth Risk Behavior Study, which included 2,730 students in grades 6 to 8 (reported ages: 11 years or younger, 12 and 13 years), across 22 San Francisco public middle schools (Shields et al., 2013). The final sample included 2,701 participants. Thirty-three children self-identified as TGD based on the question "What is your gender?', where the possible responses were 'female', 'male', or 'transgender'. The resulting proportion of TGD survey respondents was 1.3\%; the results by AMAB/AFAB status were not provided. A population-based study evaluating gender identity among 879 children (age range: 4 to 11 years, mean 7.5 years) was performed in the Netherlands in 1983 as part of a longitudinal assessment of age-related changes in gender variance and sexual orientation (Steensma, van der Ende, Verhulst, \& Cohen-Kettenis, 2013). Unlike other studies listed in Table 3, the data were collected from parents or other primary caregivers rather than from study participants. At baseline, the respondents were given the Child Behavior Checklist/4-18 (Dutch version) and were asked to rate two items "Behaves like opposite sex" and "Wishes to be of opposite sex" using a 3-point scale (range $0-2$ ). Using the score of $>0$ as the cutoff, $5.8 \%$ of children in this study were reported to exhibit gender variant behavior. The corresponding estimates for AMAB children and AFAB children were $2.5 \%$ and $8.7 \%$, respectively. 


\section{$<T A B L E$ 3> HERE}

\section{DISCUSSION}

Several previous reviews noted the pronounced heterogeneity in the reported estimates of the number and proportion of TGD people across studies (Arcelus et al., 2015; Collin et al., 2016; Goodman et al., 2019). While the main source of this heterogeneity is the difference in TGD definitions, other contributing factors include a wide range of time periods covered in different studies and the variable methods of estimating the denominator when calculating population proportions. By limiting the present review to relatively recent studies (published within the last 10 years) that assessed the proportion of the TGD population within a well-defined sampling frame we expected to observe a greater concordance of results at least for the same or similar definitions of TGD. These expectations were met to an extent. Among health system-based studies that relied on ICD codes (Blosnich et al., 2013; Dragon et al., 2017; Ewald et al., 2019; Kauth et al., 2014), the proportions of TGD people reported in recent years (2011-2016) ranged between 17 and 33 per 100,000 enrollees; whereas one study (Quinn et al., 2017), which combined diagnostic information with evidence from free text notes reported higher estimates. By contrast, when the TGD status was ascertained based on self-report the corresponding proportions were orders of magnitude higher, but also reasonably consistent, if the studies used similar definitions. When the surveys specifically inquired about "transgender" identity, the estimates ranged from $0.3 \%$ to $0.5 \%$ among adults, and from $1.2 \%$ to $2.7 \%$ in children and adolescents. When the definition was expanded to include broader manifestations of gender diversity, such as gender incongruence or gender ambivalence, the corresponding proportions increased to $0.5-4.5 \%$ among adults and $2.5-8.4 \%$ among children and adolescents. It is 
important to point out that the data on children and adolescents primarily includes the latter. Among studies that collected information on self-reported gender in the pediatric age group, all except one (Shields et al., 2013) examined high school students (i.e., persons 13-19 years of age). Even Shields et al. (2013) included some adolescents because the upper age range in that study was 13 years. Thus, our review did not identify any studies reporting the proportion of prepubertal children with self-reported TGD status. One study (Steensma et al., 2013), presented data for younger children (ages 4-11) but this study is methodologically different because it relied on parent responses to the Child Behavior Checklist rather than children's self-report. This approach is understandable given the young age of the participants. Another similarly conducted study administered the Child Behavior Checklist as part of the data collection for the longitudinal Netherlands Twin Registry (van Beijsterveldt, Hudziak, \& Boomsma, 2006). This study was not included in the main review because its publication date was outside of the period (2009-2019) covered in this review and because the data were limited to twins rather than general population. Nevertheless, the results fall within the range of those reported elsewhere. The proportions of "cross gender behavior" in that study were $3.2 \%$ and 5.2\% for 7-year-old AMAB and AFAB children, respectively. By the age of 10 , these proportions decreased to $2.4 \%$ among AMAB study participants and 3.3\% among AFAB study participants. As reviewed elsewhere (Goodman et al., 2019) studies evaluating long-term time trends consistently report changes in both the size and the demographic composition of the TGD population. Upward trends in the proportion of TGD people were observed within health care systems (Blosnich et al., 2013; Ewald et al., 2019; Quinn et al., 2017), population based surveys (Meerwijk \& Sevelius, 2017), as well as in the data on legal gender recognition (Lee, Gurr, \& Van Wye, 2017). Studies from Denmark and the Netherlands demonstrated that the median ages of the first TGD-related clinic visit and gender 
affirming surgery have both significantly decreased in recent decades (Aydin et al., 2016; Wiepjes et al., 2018). The trend towards greater proportion of TGD people in younger age groups likely represents the "cohort effect" also termed "generation effects" which is defined as variation in the population parameter according to the year of birth, often coinciding with shifts in the population characteristics over time (Keyes, Utz, Robinson, \& Li, 2010).

The temporal trends in $\mathrm{AMAB}$ to $\mathrm{AFAB}$ ratio, especially among TGD youth, have also been reported in studies analyzing referrals to clinics (Goodman et al., 2019); this ratio has changed from predominantly $\mathrm{AMAB}$ in the previous decades to predominantly $\mathrm{AFAB}$ in recent years (Aitken et al., 2015; de Graaf, Carmichael, Steensma, \& Zucker, 2018; de Graaf, Giovanardi, Zitz, \& Carmichael, 2018; Steensma, Cohen-Kettenis, \& Zucker, 2018). The reasons underlying these temporal changes are not established, but it is possible that the observed trends reflect sociopolitical and medical advances, increased access to medical care, less pronounced cultural stigma and other changes in social norms (Lee et al., 2017; Motmans, Wyverkens, \& Defreyne, 2017).

The findings of this review need to be interpreted while taking into account the limitations of the underlying literature. With respect to health system-based-studies, perhaps the most important limitation is a lack of publications from countries outside of the United States. This is surprising considering that many countries in Europe and other part of the world have well established electronic health record capture systems that can be used for this purpose. Studies that relied on self-report, although more geographically diverse, also come from a relative limited number of regions (e.g., the Netherlands, or certain areas in the US) with relatively inclusive policies, which may differ from policies and attitudes encountered in other parts of the world. Another, perhaps more important, limitation of self-reported data is the less than complete response rate, which 
ranged between $21 \%$ and $90 \%$. Although it has been suggested that lower response rates are expected to underestimate the size of the TGD population because TGD people are less inclined to participate in surveys (Kuyper and Wijsen, 2014), the accuracy of this expectation requires verification.

These limitations notwithstanding, the available data clearly indicate that people who selfidentify as TGD represent a sizable and increasing proportion of the general population. Based on the credible evidence available to date, this proportion may range from a fraction of a percent to several percentage points, depending on inclusion criteria, participant age, and geographic location. Accurate estimates of the proportion, distribution and composition of the TGD population, as well as projection of resources required to adequately support health needs of TGD people will ultimately depend on the availability of systematically collected high-quality data. Such systematic data collection is needed to decrease variability and minimize over- and under-estimation of reported results stemming from the lack of agreed upon definitions. For example, far more accurate and precise estimates should become available if population censuses begin systematically collecting data on both sex assigned at birth and gender identity, including non-binary categories, using the now well-validated two-step method.

\section{Declaration of conflict of interest}

The authors declare that they have no conflict of interest 


\section{References}

Adams, N., Pearce, R., Veale, J., Radix, A., Castro, D., Sarkar, A., \& Thom, K. C. (2017). Guidance and Ethical Considerations for Undertaking Transgender Health Research and Institutional Review Boards Adjudicating this Research. Transgend Health, 2(1), 165175. doi:10.1089/trgh.2017.0012

Ahs, J. W., Dhejne, C., Magnusson, C., Dal, H., Lundin, A., Arver, S., . . Kosidou, K. (2018). Proportion of adults in the general population of Stockholm County who want genderaffirming medical treatment. PloS One, 13(10), e0204606. doi:10.1371/journal.pone.0204606

Aitken, M., Steensma, T. D., Blanchard, R., VanderLaan, D. P., Wood, H., Fuentes, A., . . . Zucker, K. J. (2015). Evidence for an altered sex ratio in clinic-referred adolescents with gender dysphoria. J Sex Med, 12(3), 756-763. doi:10.1111/jsm.12817

Almeida, J., Johnson, R. M., Corliss, H. L., Molnar, B. E., \& Azrael, D. (2009). Emotional distress among LGBT youth: the influence of perceived discrimination based on sexual orientation. J Youth Adolesc, 38(7), 1001-1014. doi:10.1007/s10964-009-9397-9

Arcelus, J., Bouman, W. P., Van Den Noortgate, W., Claes, L., Witcomb, G., \& FernandezAranda, F. (2015). Systematic review and meta-analysis of prevalence studies in transsexualism. Eur Psychiatry. doi:10.1016/j.eurpsy.2015.04.005

Aydin, D., Buk, L. J., Partoft, S., Bonde, C., Thomsen, M. V., \& Tos, T. (2016). Transgender Surgery in Denmark From 1994 to 2015: 20-Year Follow-Up Study. J Sex Med, 13(4), 720-725. doi:10.1016/j.jsxm.2016.01.012

Blosnich, J. R., Brown, G. R., Shipherd Phd, J. C., Kauth, M. R., Piegari, R. I., \& Bossarte, R. M. (2013). Prevalence of gender identity disorder and suicide risk among transgender veterans utilizing veterans health administration care. Am J Public Health, 103(10), e2732. doi:10.2105/AJPH.2013.301507

Bouman, W. P., Schwend, A. S., Motmans, J., Smiley, A., Safer, J. D., Deutsch, M. B., . . . Winter, S. (2017). Language and trans health. Int J Transgender, 18(1), 1-6.

Clark, T. C., Lucassen, M. F., Bullen, P., Denny, S. J., Fleming, T. M., Robinson, E. M., \& Rossen, F. V. (2014). The health and well-being of transgender high school students: results from the New Zealand adolescent health survey (Youth'12). J Adolesc Health, 55(1), 93-99. doi:10.1016/j.jadohealth.2013.11.008

Coleman, E., Bockting, W. O., Botzer, M., Cohen-Kettenis, P., DeCuypere, G., Feldman, J., . . . Meyer, W. (2012). Standards of care for the health of transsexual, transgender, and gender-nonconforming people, version 7. Int J Transgender, 13(4), 165-232.

Collin, L., Reisner, S. L., Tangpricha, V., \& Goodman, M. (2016). Prevalence of Transgender Depends on the "Case" Definition: A Systematic Review. J Sex Med, 13(4), 613-626. doi:10.1016/j.jsxm.2016.02.001

Conron, K. J., Scott, G., Stowell, G. S., \& Landers, S. J. (2012). Transgender health in Massachusetts: results from a household probability sample of adults. Am J Public Health, 102(1), 118-122. doi:10.2105/ajph.2011.300315 
Crissman, H. P., Berger, M. B., Graham, L. F., \& Dalton, V. K. (2017). Transgender Demographics: A Household Probability Sample of US Adults, 2014. Am J Public Health, 107(2), 213-215. doi:10.2105/AJPH.2016.303571

de Graaf, N. M., Carmichael, P., Steensma, T. D., \& Zucker, K. J. (2018). Evidence for a Change in the Sex Ratio of Children Referred for Gender Dysphoria: Data From the Gender Identity Development Service in London (2000-2017). J Sex Med, 15(10), 1381-1383. doi:10.1016/j.jsxm.2018.08.002

de Graaf, N. M., Giovanardi, G., Zitz, C., \& Carmichael, P. (2018). Sex Ratio in Children and Adolescents Referred to the Gender Identity Development Service in the UK (20092016). Arch Sex Behav, 47(5), 1301-1304. doi:10.1007/s10508-018-1204-9

Deutsch, M. B. (2016). Making It Count: Improving Estimates of the Size of Transgender and Gender Nonconforming Populations. LGBT Health, 3(3), 181-185.

doi:10.1089/lgbt.2016.0013

Dragon, C. N., Guerino, P., Ewald, E., \& Laffan, A. M. (2017). Transgender Medicare Beneficiaries and Chronic Conditions: Exploring Fee-for-Service Claims Data. LGBT Health, 4(6), 404-411. doi:10.1089/lgbt.2016.0208

Eisenberg, M. E., Gower, A. L., McMorris, B. J., Rider, G. N., Shea, G., \& Coleman, E. (2017). Risk and Protective Factors in the Lives of Transgender/Gender Nonconforming Adolescents. J Adolesc Health, 61(4), 521-526. doi:10.1016/j.jadohealth.2017.04.014

Ewald, E. R., Guerino, P., Dragon, C., Laffan, A. M., Goldstein, Z., \& Streed, C., Jr. (2019). Identifying Medicare Beneficiaries Accessing Transgender-Related Care in the Era of ICD-10. LGBT Health, 6(4), 166-173. doi:10.1089/lgbt.2018.0175

Goodman, M., Adams, N., Corneil, T., Kreukels, B., Motmans, J., \& Coleman, E. (2019). Size and Distribution of Transgender and Gender Nonconforming Populations: A Narrative Review. Endocrinol Metab Clin North Am, 48(2), 303-321.

doi:10.1016/j.ecl.2019.01.001

Grasso, C., Goldhammer, H., Funk, D., King, D., Reisner, S. L., Mayer, K. H., \& Keuroghlian, A. S. (2019). Required Sexual Orientation and Gender Identity Reporting by US Health Centers: First-Year Data. Am J Public Health, 109(8), 1111-1118. doi:10.2105/ajph.2019.305130

Kauth, M. R., Shipherd, J. C., Lindsay, J., Blosnich, J. R., Brown, G. R., \& Jones, K. T. (2014). Access to care for transgender veterans in the Veterans Health Administration: 20062013. Am J Public Health, 104 Suppl 4, S532-534. doi:10.2105/ajph.2014.302086

Keyes, K. M., Utz, R. L., Robinson, W., \& Li, G. (2010). What is a cohort effect? Comparison of three statistical methods for modeling cohort effects in obesity prevalence in the United States, 1971-2006. Soc Sci Med, 70(7), 1100-1108. doi:10.1016/j.socscimed.2009.12.018

Koebnick, C., Langer-Gould, A. M., Gould, M. K., Chao, C. R., Iyer, R. L., Smith, N., . . . Jacobsen, S. J. (2012). Sociodemographic characteristics of members of a large, integrated health care system: comparison with US Census Bureau data. Perm J, 16(3), $37-41$. 
Kuyper, L., \& Wijsen, C. (2014). Gender identities and gender dysphoria in the Netherlands. Arch Sex Behav, 43(2), 377-385. doi:10.1007/s10508-013-0140-y

Lai, M. C., Chiu, Y. N., Gadow, K. D., Gau, S. S., \& Hwu, H. G. (2010). Correlates of gender dysphoria in Taiwanese university students. Arch Sex Behav, 39(6), 1415-1428. doi:10.1007/s10508-009-9570-y

Lee, E. J., Gurr, D., \& Van Wye, G. (2017). An Evaluation of New York City's 2015 Birth Certificate Gender Marker Regulation. LGBT Health, 4(5), 320-327. doi:10.1089/lgbt.2017.0087

Lowry, R., Johns, M. M., Gordon, A. R., Austin, S. B., Robin, L. E., \& Kann, L. K. (2018). Nonconforming Gender Expression and Associated Mental Distress and Substance Use Among High School Students. JAMA Pediatr, 172(11), 1020-1028. doi:10.1001/jamapediatrics.2018.2140

Meerwijk, E. L., \& Sevelius, J. M. (2017). Transgender Population Size in the United States: a Meta-Regression of Population-Based Probability Samples. Am J Public Health, 107(2), e1-e8. doi:10.2105/AJPH.2016.303578

Meier, S. C., \& Labuski, C. M. (2013). The demographics of the transgender population. In International Handbook on the Demography of Sexuality (pp. 289-327): Springer.

Moher, D., Liberati, A., Tetzlaff, J., \& Altman, D. G. (2009). Preferred reporting items for systematic reviews and meta-analyses: the PRISMA statement. BMJ, 339, b2535. doi:10.1136/bmj.b2535

Motmans, J., Wyverkens, E., \& Defreyne, J. (2017). Being transgender in Belgium. Ten years later. Institute for the Equality of Women and Men. Brussels, Belgium

Quinn, V. P., Nash, R., Hunkeler, E., Contreras, R., Cromwell, L., Becerra-Culqui, T. A., . . Goodman, M. (2017). Cohort profile: Study of Transition, Outcomes and Gender (STRONG) to assess health status of transgender people. BMJ Open, 7(12), e018121. doi:10.1136/bmjopen-2017-018121

Reisner, S. L., Biello, K., Rosenberger, J. G., Austin, S. B., Haneuse, S., Perez-Brumer, A., . . . Mimiaga, M. J. (2014). Using a two-step method to measure transgender identity in Latin America/the Caribbean, Portugal, and Spain. Arch Sex Behav, 43(8), 1503-1514. doi:10.1007/s10508-014-0314-2

Reisner, S. L., Conron, K. J., Tardiff, L. A., Jarvi, S., Gordon, A. R., \& Austin, S. B. (2014). Monitoring the health of transgender and other gender minority populations: validity of natal sex and gender identity survey items in a U.S. national cohort of young adults. BMC Public Health, 14, 1224. doi:10.1186/1471-2458-14-1224

Shields, J. P., Cohen, R., Glassman, J. R., Whitaker, K., Franks, H., \& Bertolini, I. (2013). Estimating population size and demographic characteristics of lesbian, gay, bisexual, and transgender youth in middle school. J Adolesc Health, 52(2), 248-250. doi:10.1016/j.jadohealth.2012.06.016

Steensma, T. D., Cohen-Kettenis, P. T., \& Zucker, K. J. (2018). Evidence for a Change in the Sex Ratio of Children Referred for Gender Dysphoria: Data from the Center of Expertise 
on Gender Dysphoria in Amsterdam (1988-2016). J Sex Marital Ther, 44(7), 713-715. doi:10.1080/0092623x.2018.1437580

Steensma, T. D., van der Ende, J., Verhulst, F. C., \& Cohen-Kettenis, P. T. (2013). Gender variance in childhood and sexual orientation in adulthood: a prospective study. $J$ Sex Med, 10(11), 2723-2733. doi:10.1111/j.1743-6109.2012.02701.x

Tate, C. C., Ledbetter, J. N., \& Youssef, C. P. (2013). A two-question method for assessing gender categories in the social and medical sciences. J Sex Res, 50(8), 767-776. doi:10.1080/00224499.2012.690110

US Centers for Medicare \& Medicaid Services. (2004). What's Medicare? Available at: https://www.medicare.gov/what-medicare-covers/your-medicare-coveragechoices/whats-medicare. Accessed 03/02/2020.

US Department of Veterans Affairs. (2019). About VHA. Available at: http://www.va.gov/health/. Accessed 03/02/2020.

van Beijsterveldt, C. E., Hudziak, J. J., \& Boomsma, D. I. (2006). Genetic and environmental influences on cross-gender behavior and relation to behavior problems: a study of Dutch twins at ages 7 and 10 years. Arch Sex Behav, 35(6), 647-658. doi:10.1007/s10508-0069072-0

Van Caenegem, E., Wierckx, K., Elaut, E., Buysse, A., Dewaele, A., Van Nieuwerburgh, F., .. . T'Sjoen, G. (2015). Prevalence of Gender Nonconformity in Flanders, Belgium. Arch Sex Behav, 44(5), 1281-1287. doi:10.1007/s10508-014-0452-6

Wiepjes, C. M., Nota, N. M., de Blok, C. J. M., Klaver, M., de Vries, A. L. C., Wensing-Kruger, S. A., . . den Heijer, M. (2018). The Amsterdam Cohort of Gender Dysphoria Study (1972-2015): Trends in Prevalence, Treatment, and Regrets. J Sex Med, 15(4), 582-590. doi:10.1016/j.jsxm.2018.01.016

World Health Organization. (1978). International classification of diseases. Ninth revision. Geneva: World Health Organization.

World Health Organization. (1992). International classification of diseases. Tenth revision. Geneva: World Health Organization. 


\section{TABLES AND FIGURES}

Figure 1: PRISMA diagram of article selection
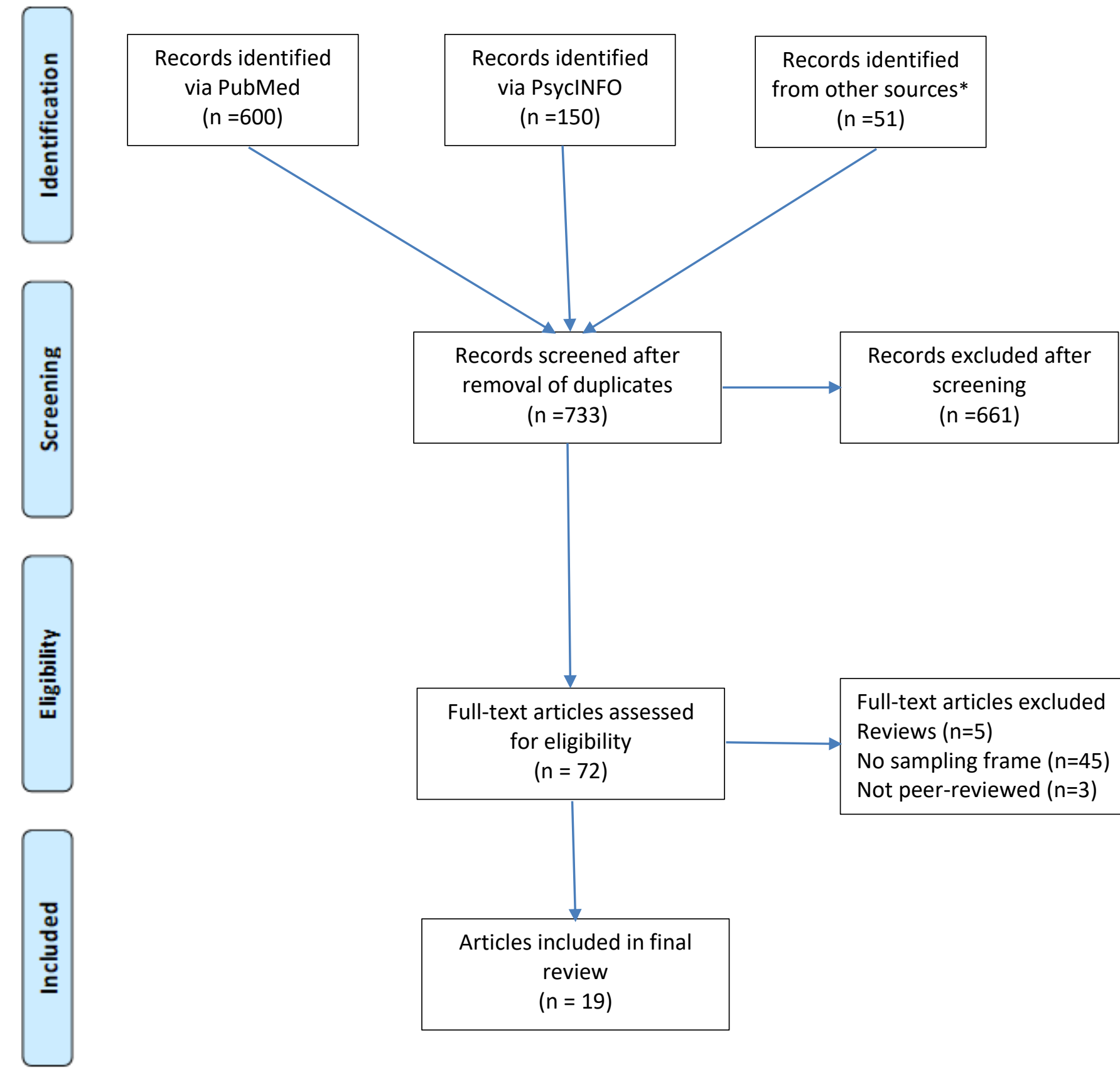

Full-text articles excluded Reviews ( $n=5$ )

No sampling frame $(n=45)$ Not peer-reviewed $(n=3)$

PRISMA = Preferred Reporting Items for Systematic Reviews and Meta-Analyses (Moher et al., 2009).

*Other sources include secondary references of retrieved articles and references included in earlier reviews 
Table 1: Number and population proportion of TGD individuals identified in health care systems

\begin{tabular}{|c|c|c|c|c|c|}
\hline $\begin{array}{l}\text { Health system, country, time } \\
\text { period, (Reference) }\end{array}$ & Case definition & $\begin{array}{l}\text { Source of } \\
\text { numerator }\end{array}$ & Numerator & Source and size of denominator & $\begin{array}{c}\text { Proportion } \\
\text { (per 100,000) }\end{array}$ \\
\hline $\begin{array}{l}\text { VHA system, US, 2002-2011 } \\
\text { (Blosnich et al., 2013) }\end{array}$ & ICD-9 codes 302.85 or 302.6 & $\begin{array}{l}\text { Electronic medical } \\
\text { records }\end{array}$ & $\begin{array}{l}\text { 2002: } 569 \\
\text { 2011: } 1329\end{array}$ & $\begin{array}{l}\text { Total VA patients } \\
4,544,353(2002), \\
5,795,165(2011)\end{array}$ & $\begin{array}{l}\text { 2002: } 13 \\
\text { 2011: } 23\end{array}$ \\
\hline $\begin{array}{l}\text { VHA system, US, } 2013 \text { (Kauth et al., } \\
\text { 2014) }\end{array}$ & $\begin{array}{l}\text { ICD-9 codes 302.85, 302.6, } \\
302.5\end{array}$ & $\begin{array}{l}\text { Electronic medical } \\
\text { records }\end{array}$ & 2567 & Total VA patients $7,809,269$ & 33 \\
\hline $\begin{array}{l}\text { Kaiser Permanente Northern } \\
\text { California (KPNC), Northern } \\
\text { California (KPSC) and Georgia } \\
\text { (KPGA), US, 2006-2014 (Quinn et al., } \\
2017)\end{array}$ & $\begin{array}{l}\text { Transgender-specific diagnoses } \\
\text { or free-text keywords in health } \\
\text { records }\end{array}$ & $\begin{array}{l}\text { Electronic medical } \\
\text { records) }\end{array}$ & $\begin{array}{c}2006 \\
\text { KPGA: } 12 \\
\text { KPSC: } 205 \\
\text { KPNC: } 601 \\
2014 \\
\text { KPGA: } 125 \\
\text { KPSC: } 1879 \\
\text { KPNC: } 2897\end{array}$ & $\begin{array}{c}\text { All members enrolled in a given year } \\
2006 \\
\text { KPGA: } 340,909 \\
\text { KPSC: } 3,698,661 \\
\text { KPNC: } 3,545,776 \\
2014 \\
\text { KPGA: } 330,727 \\
\text { KPSC: } 4,243,718 \\
\text { KPNC: } 3,868,415\end{array}$ & $\begin{array}{c}2006 \\
\text { KPGA: } 3.5 \\
\text { KPSC: } 5.5 \\
\text { KPNC: } 17 \\
2014 \\
\text { KPGA: } 38 \\
\text { KPSC: } 44 \\
\text { KPNC: } 75\end{array}$ \\
\hline $\begin{array}{l}\text { Medicare, US, } 2015 \text { (Dragon et al., } \\
\text { 2017) }\end{array}$ & $\begin{array}{l}\text { ICD-9 codes } 302.5 x, 302.6 \text {, } \\
302.85\end{array}$ & $\begin{array}{l}\text { Medicare Fee } \\
\text { For Service } \\
\text { claims }\end{array}$ & 7454 & $\begin{array}{l}\text { Total Medicare population } \\
\text { (excluding those with end-stage } \\
\text { renal disease } \\
39,136,229\end{array}$ & 19 \\
\hline $\begin{array}{l}\text { Medicare, US 2010-2016 (Ewald et } \\
\text { al., 2019) }\end{array}$ & $\begin{array}{l}\text { ICD-9 codes } 302.5 x, 302.6, \\
302.85 \\
\text { ICD-10 codes F64.1, F64.2, } \\
\text { F64.8, F64.9, Z87.890 }\end{array}$ & $\begin{array}{l}\text { Medicare Fee } \\
\text { For Service } \\
\text { claims }\end{array}$ & $\begin{array}{l}\text { 2010: } 2088 \\
\text { 2016: } 10242\end{array}$ & $\begin{array}{l}\text { Total Medicare population* } \\
\text { 2010: } 49,714,286 \\
\text { 2016: } 60,247,059\end{array}$ & $\begin{array}{l}2010: 4.2 \\
2016: 17\end{array}$ \\
\hline
\end{tabular}

*Denominator calculated from the numerator and the reported proportion

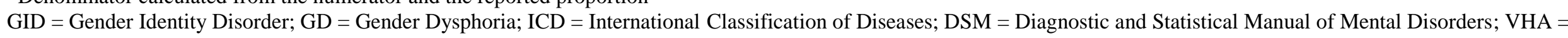
Veterans Health Administration 
Table 2: Number and population proportion of adults who self-reported transgender identity or gender diversity

\begin{tabular}{|c|c|c|c|c|c|c|c|c|c|}
\hline \multirow{2}{*}{$\begin{array}{l}\text { Survey location; time period, } \\
\text { age (Reference) }\end{array}$} & \multirow{2}{*}{ Case definition } & \multirow{2}{*}{$\begin{array}{l}\text { Source of } \\
\text { numerator }\end{array}$} & \multicolumn{3}{|c|}{ Numerator } & \multirow[t]{2}{*}{$\begin{array}{l}\text { Size of } \\
\text { denominator }\end{array}$} & \multicolumn{3}{|c|}{ Percentage } \\
\hline & & & Total & RMAB & RFAB & & Total & RMAB & RFAB \\
\hline $\begin{array}{l}\text { Stockholm County, Sweden, } \\
2014, \geq 22 \text { years (Ahs et al., } \\
2018 \text { ) }\end{array}$ & $\begin{array}{l}\begin{array}{l}\text { Desire to undergo } \\
\text { treatment }\end{array} \\
\text { Feeling as person of } \\
\text { different sex } \\
\text { Desire to be treated } \\
\text { as person of different } \\
\text { sex }\end{array}$ & $\begin{array}{l}\text { Stockholm } \\
\text { Public Health } \\
\text { Cohort (SPHC) } \\
\text { study } \\
\text { questionnaire }\end{array}$ & $\begin{array}{l}121 \\
770 \\
779 \\
\end{array}$ & $\begin{array}{l}309 \\
218\end{array}$ & $\begin{array}{r}61 \\
461 \\
\\
561 \\
\end{array}$ & $\begin{array}{l}50,157 ; 21,586 \\
\text { males and 28,571 } \\
\text { females }\end{array}$ & $\begin{array}{l}0.5 \% \\
2.3 \% \\
2.8 \%\end{array}$ & $\begin{array}{l}0.6 \% \\
2.1 \% \\
\\
2.0 \%\end{array}$ & $\begin{array}{l}0.4 \% \\
2.5 \% \\
3.5 \%\end{array}$ \\
\hline $\begin{array}{l}\text { Massachusetts, US, 2007-2009, } \\
\text { 18-64 years (Conron et al., } \\
\text { 2012) }\end{array}$ & $\begin{array}{l}\text { Self-identity as } \\
\text { transgender }\end{array}$ & $\begin{array}{l}\text { Massachusetts } \\
\text { Behavioral Risk } \\
\text { Factor } \\
\text { Surveillance } \\
\text { Survey (BRFSS) } \\
2007-2009 \\
\end{array}$ & 131 & NA & NA & 28,176 & $0.5 \%$ & NA & NA \\
\hline $\begin{array}{l}\text { Nationwide, US, 2014, } \geq 18 \\
\text { years (Crissman et al., 2017) }\end{array}$ & $\begin{array}{l}\text { Self-identity as } \\
\text { transgender }\end{array}$ & $\begin{array}{l}\text { Annual cross- } \\
\text { sectional } \\
\text { telephone } \\
\text { survey in all US } \\
\text { states and } 3 \\
\text { territories }\end{array}$ & $\begin{array}{c}\text { TGD: } \\
807 \\
\text { Trans: } \\
691\end{array}$ & $\begin{array}{c}\text { Trans: } \\
363\end{array}$ & $\begin{array}{c}\text { Trans: } \\
212\end{array}$ & $\begin{array}{l}151,456(62,086 \\
\text { cisgender males, } \\
88,679 \text { cisgender } \\
\text { females })\end{array}$ & $\begin{array}{l}\text { TGD } 0.5 \% \\
\text { Trans: } 0.5 \%\end{array}$ & $0.6 \%$ & $0.2 \%$ \\
\hline $\begin{array}{l}\text { Nationwide, Netherlands, 2013, } \\
\text { 15-70 years (Kuyper \& Wijsen, } \\
2014)^{*}\end{array}$ & $\begin{array}{l}\text { Incongruent gender } \\
\text { identity } \\
\text { Ambivalent gender } \\
\text { identity }\end{array}$ & $\begin{array}{l}\text { Sexual Health } \\
\text { Survey }\end{array}$ & $\begin{array}{l}77^{* *} \\
315^{* *}\end{array}$ & $\begin{array}{l}45^{* * *} \\
186^{* * *}\end{array}$ & $\begin{array}{l}32 * * \\
128 * *\end{array}$ & $\begin{array}{l}8,064 \text { total }(4052 \\
\text { males, } 4012 \\
\text { females })\end{array}$ & $\begin{array}{l}1.0 \% \\
3.9 \%\end{array}$ & $\begin{array}{l}1.1 \% \\
4.6 \%\end{array}$ & $\begin{array}{l}0.8 \% \\
3.2 \%\end{array}$ \\
\hline $\begin{array}{l}\text { Taiwan University, Taiwan } \\
\text { 2003-2004, first-year college } \\
\text { students (Lai et al., 2010) }\end{array}$ & $\begin{array}{l}\text { Self-reported gender } \\
\text { dysphoria }\end{array}$ & $\begin{array}{l}\text { Adult Self- } \\
\text { Report } \\
\text { Inventory-4, } \\
\text { DSM-IV } \\
\text { referenced } \\
\text { rating }\end{array}$ & 225 & 49 & 176 & $\begin{array}{l}5010 \text { total }(2585 \\
\text { males, } 2425 \\
\text { females })\end{array}$ & $4.5 \%$ & $1.9 \%$ & $7.3 \%$ \\
\hline $\begin{array}{l}\text { Nationwide, US, 2010, 23-28 } \\
\text { years (Reisner, Conron, et al., } \\
\text { 2014) }\end{array}$ & $\begin{array}{l}\text { Self-identity as } \\
\text { transgender }\end{array}$ & $\begin{array}{l}\text { Growing Up } \\
\text { Today Study } \\
\text { (GUTS) }\end{array}$ & 26 & 10 & 16 & $\begin{array}{l}\text { 7,831 (2,605 males, } \\
\text { and 5,226 females) }\end{array}$ & $0.3 \%$ & $0.4 \%$ & $0.3 \%$ \\
\hline $\begin{array}{l}\text { Flanders, Belgium, 14-80 } \\
\text { years, 2011-2012 (Van } \\
\text { Caenegem et al., 2015)* }\end{array}$ & $\begin{array}{l}\text { Incongruent gender } \\
\text { identity } \\
\text { Ambivalent gender } \\
\text { identity }\end{array}$ & $\begin{array}{l}\text { Sexual Health } \\
\text { Survey }\end{array}$ & $\begin{array}{l}11 * * \\
37 * *\end{array}$ & $\begin{array}{l}\text { ** } \\
17 * *\end{array}$ & $\begin{array}{l}6^{* *} \\
20^{* *}\end{array}$ & $\begin{array}{l}1,799 \text { ( } 894 \text { males, } \\
905 \text { females) }\end{array}$ & $\begin{array}{l}0.6 \% \\
2.0 \%\end{array}$ & $\begin{array}{l}0.7 \% \\
2.2 \%\end{array}$ & $\begin{array}{l}0.6 \% \\
1.9 \%\end{array}$ \\
\hline
\end{tabular}




\begin{tabular}{|c|c|c|c|c|c|c|c|c|c|}
\hline $\begin{array}{l}\text { San Francisco, US, 18-71 } \\
\text { years, } 2013 \text { (Tate et al., 2013) }\end{array}$ & $\begin{array}{l}\text { One question about } \\
\text { gender (Study 1) } \\
\text { Two questions about } \\
\text { sex recorded at birth } \\
\text { and gender identity } \\
\text { (Studies } 2 \text { and 3) }\end{array}$ & $\begin{array}{l}\text { San Francisco } \\
\text { State University, } \\
\text { Department of } \\
\text { Psychology } \\
\text { Survey }\end{array}$ & $\begin{array}{l}\text { Study } 1: 2 \\
\text { Study 2: } 6 \text { (2 } \\
\text { transgender, } 4 \\
\text { non-binary) } \\
\text { Study } 3: 12 \text { (6 } \\
\text { transgender, } 6 \\
\text { non-binary) }\end{array}$ & $\begin{array}{l}\text { Study 1: } \\
\text { NA } \\
\text { Study 2: } \\
\text { NA } \\
\text { Study 3: } \\
3 \text { transwomen }\end{array}$ & $\begin{array}{l}\text { Study 1: } \\
\text { NA } \\
\text { Study 2: } \\
2 \text { transmen } \\
\text { Study 3: } \\
3 \text { transmen }\end{array}$ & $\begin{array}{l}\text { Study 1: } 238 \\
\begin{array}{l}\text { Study 2: } 364 \text { ( } 259 \\
\text { cisgender females, } \\
99 \text { cisgender males) } \\
\text { Study 3: } 388 \text { (192 } \\
\text { cisgender females, } \\
\text { 184 cisgender } \\
\text { males) }\end{array}\end{array}$ & $\begin{array}{c}\text { Study 1: } \\
0.8 \% \\
\\
\text { Study 2: } \\
1.6 \% \\
\\
\text { Study 3: } \\
3.1 \%\end{array}$ & $\begin{array}{l}\text { Study 1: } \\
\text { NA } \\
\text { Study 2: } \\
\text { NA } \\
\\
\text { Study 3: } \\
1.6 \%\end{array}$ & $\begin{array}{c}\text { Study 1: } \\
\text { NA } \\
\text { Study 2: } \\
0.8^{\ddagger} \\
\\
\text { Study 3: } \\
1.6^{\ddagger}\end{array}$ \\
\hline
\end{tabular}

*Includes a small proportion of adolescents, but the reported data do not allow evaluating results by age

**Calculated based on reported percentages and denominator sizes

$\$$ Results exclude non-binary participants whose sex recorded at birth is not known

$\mathrm{NA}=$ Not available 
Table 3: Number and population proportion of children and adolescents with self- or parent-reported transgender identity and gender diversity

\begin{tabular}{|c|c|c|c|c|c|c|c|c|c|}
\hline \multirow{2}{*}{$\begin{array}{l}\text { Survey location; time period, age } \\
\text { (Reference) }\end{array}$} & \multirow{2}{*}{$\begin{array}{l}\text { Case } \\
\text { definition }\end{array}$} & \multirow{2}{*}{ Source of numerator } & \multicolumn{3}{|c|}{ Numerator } & \multirow{2}{*}{$\begin{array}{l}\text { Size of } \\
\text { denominator }\end{array}$} & \multicolumn{3}{|c|}{ Percentage } \\
\hline & & & Total & AMAB & AFAB & & Total & AMAB & AFAB \\
\hline $\begin{array}{l}\text { Boston, Massachusetts, US, 2006, } \\
\text { 13-19 years (Almeida et al., 2009) }\end{array}$ & $\begin{array}{l}\text { Self-identity as } \\
\text { transgender }\end{array}$ & $\begin{array}{l}\text { Boston Youth Survey } \\
\text { data }\end{array}$ & 17 & 11 & 6 & 1032 & $1.6 \%$ & NA & NA \\
\hline $\begin{array}{l}\text { Nationwide, New Zealand, } 2012 \text {, } \\
\text { secondary school students; age } \\
\text { range not provided; } 65 \% \text { reported } \\
\text { to be } \leq 15 \text { years of age (Clark et al., } \\
2014 \text { ) }\end{array}$ & $\begin{array}{l}\text { Self-identity as } \\
\text { transgender } \\
\text { Not sure of } \\
\text { gender identity }\end{array}$ & $\begin{array}{l}\text { National survey of } \\
\text { secondary school } \\
\text { students }\end{array}$ & $\begin{array}{l}96 \\
201\end{array}$ & $\begin{array}{l}44 \\
82\end{array}$ & $\begin{array}{l}52 \\
120\end{array}$ & $\begin{array}{l}8164(3669 \\
\text { males, } 4495 \\
\text { females })\end{array}$ & $\begin{array}{l}1.2 \% \\
2.5 \%\end{array}$ & $\begin{array}{l}1.2 \% \\
2.2 \%\end{array}$ & $1.2 \%$ \\
\hline $\begin{array}{l}\text { Minnesota, USA, 2016, } 9^{\text {th }} \text { and } \\
11^{\text {th }} \text { grade (Eisenberg et al., 2017) }\end{array}$ & $\begin{array}{l}\text { Self-identity as } \\
\text { transgender }\end{array}$ & $\begin{array}{l}\text { Minnesota Student } \\
\text { Survey }\end{array}$ & 2,198 & NA & NA & 80,929 & $2.7 \%$ & $1.7 \%$ & $3.6 \%$ \\
\hline $\begin{array}{l}\text { San Francisco, US, 2011, 11-13 } \\
\text { years (Shields et al., 2013) }\end{array}$ & $\begin{array}{l}\text { Self-identity as } \\
\text { transgender }\end{array}$ & $\begin{array}{l}\text { Youth Risk Behavior } \\
\text { Survey at administered in } \\
\text { middle schools }\end{array}$ & 33 & NA & $\mathrm{NA}$ & 2701 & $1.3 \%$ & NA & NA \\
\hline $\begin{array}{l}\text { Zuid-Holland province, } \\
\text { Netherlands, 1983, 4-11 years } \\
\text { (Steensma et al., 2013) }\end{array}$ & $\begin{array}{l}\text { Parent/primary } \\
\text { caregiver } \\
\text { report on } \\
\text { gender } \\
\text { variance }\end{array}$ & $\begin{array}{l}\text { Baseline assessment in a } \\
\text { longitudinal study of } \\
\text { changes in sexual } \\
\text { orientation and gender } \\
\text { variant behavior }\end{array}$ & 51 & 10 & 41 & $\begin{array}{l}879(406 \\
\text { males, } 473 \\
\text { females })\end{array}$ & $5.8 \%$ & $2.5 \%$ & $8.7 \%$ \\
\hline $\begin{array}{l}\text { Florida and California, US, 2015, } \\
9-12^{\text {th }} \text { grade (Lowry et al., 2018) }\end{array}$ & $\begin{array}{l}\text { High gender } \\
\text { nonconformity } \\
\text { based on a } \\
\text { 7-point scale }\end{array}$ & $\begin{array}{l}\text { Youth Risk Behavior } \\
\text { Surveillance System }\end{array}$ & $511^{*}$ & $408^{*}$ & $117^{*}$ & $\begin{array}{l}6082(2919 \\
\text { females, } 3139 \\
\text { males)** }\end{array}$ & $8.4 \%$ & $13.0 \%$ & $4.0 \%$ \\
\hline
\end{tabular}

*Calculated based on reported percentages and denominator sizes

** Numbers of male and female participants reported in the article do not add up to total

$\mathrm{NA}=$ Not available 